\title{
TRITRICHOMONAS FOETUS AND NOT PENTATRICHOMONAS HOMINIS IS THE ETIOLOGIC AGENT OF FELINE TRICHOMONAL DIARRHEA
}

\author{
Michael G. Levy, Jody L. Gookin*, Matthew Poore, Adam J. Birkenheuer†, Michael J. Dykstra, and R. Wayne Litakerł \\ Department of Farm Animal and Health Resource Management, North Carolina State University College of Veterinary Medicine, 4700 \\ Hillsborough Street, Raleigh, North Carolina 27606-1499. e-mail: mike_levy@ncsu.edu
}

\begin{abstract}
Recently, several investigators have reported large-bowel diarrhea in cats associated with intestinal trichomonad parasites. These reports have presumptively identified the flagellates as Pentatrichomonas hominis, an organism putatively capable of infecting the intestinal tracts of a number of mammalian hosts, including cats, dogs, and man. The purpose of the present study was to determine the identity of this recently recognized flagellate by means of rRNA gene sequence analysis; restriction enzyme digest mapping; and light, transmission, and scanning electron microscopy (SEM).
\end{abstract}

Isolates of the naturally occurring feline trichomonad and Pentatrichomonas hominis were axenically cultured. DNA was extracted and rRNA genes were amplified by polymerase chain reaction (PCR), using conserved oligonucleotide primers. Restriction enzyme digests of the PCR-amplified products were performed. Cultured feline trichomonads were examined using SEM, and light and transmission electron microscopy. Examination of the rRNA genes of 3 geographically distinct isolates from cats with trichomonad-associated chronic large-bowel diarrhea revealed $99.7-100 \%$ sequence identity with Tritrichomonas foetus. Polymerase chain reaction-restriction fragment length polymorphism (RFLP) results for the feline trichomonad gave the expected pattern for $T$. foetus. Light, scanning, and transmission electron microscopic analyses of cultured feline trichomonads revealed 3 anterior flagella and axostyle morphology indistinguishable from earlier descriptions of $T$. foetus. These data identify the causative agent of feline trichomonosis as $T$. foetus.

In the cat, large-bowel diarrhea may result from a variety of infectious and noninfectious causes. Recently, several investigators have recognized an association between feline largebowel diarrhea and trichomonad infection (Romatowski, 1996, 2000; Gookin et al., 1999). These reports have tentatively identified the trichomonads as $P$. hominis, an intestinal lumendwelling flagellate described as infectious to a wide variety of hosts, including cats, dogs, and humans (Levine, 1973). Earlier reports regarding the pathogenicity of intestinal trichomonads in the cat are in conflict (Brumpt, 1925; Kessel, 1928; Henger and Eskridge, 1935), and most current veterinary textbooks do not regard trichomonads as primary pathogens. Historically, the detection of trichomonads in feces from cats with diarrhea has been rare and has been attributed to an overgrowth of endogenous fauna. (Dimski, 1989; Burrows et al., 1995; Barr, 1998). However, our laboratory has received reports of serious trichomonad diarrheal infections in cats from 12 geographically iso-

Received 1 April 2002; revised 2 August 2002; accepted 2 August 2002.

* Department of Molecular Biomedical Sciences, North Carolina State University College of Veterinary Medicine, 4700 Hillsborough Street, Raleigh, North Carolina 27606-1499.

$\dagger$ Department of Clinical Sciences, North Carolina University College of Veterinary Medicine, 4700 Hillsborough Street, Raleigh, North Carolina 27606-1499.

$\ddagger$ Center for Coastal Fisheries and Habitat Research, National Ocean Service, NOAA, 101 Pivers Island Road, Beaufort, North Carolina 28516-9722, and Program in Molecular Biology and Biotechnology, University of North Carolina, Chapel Hill, North Carolina 275997100. lated states ranging from Alaska to Florida. We have recently demonstrated that experimental infection of specific pathogenfree (SPF) cats with axenically cultured trichomonads isolated from a naturally infected kitten produced large-bowel diarrhea consistent with recently observed natural infections (Gookin et al., 2001).

Early descriptions of $P$. hominis describe isolates as having 3 , 4, or 5 anterior flagella (Levine, 1973). Using light microscopy we observed trophozoites from naturally infected cats as having predominantly 3 anterior flagella. The difference in the number of flagella observed raised questions regarding the actual identity of the feline trichomonad. The purpose of this investigation was to identify the feline pathogen definitively by means of light and electron microscopic morphology, comparative RFLP analysis, and rRNA gene analysis.

\section{MATERIALS AND METHODS}

\section{Parasites}

Trichomonads were isolated from 3 different diarrheic domestic cats (Felis catus). There was no indication of prior contact between the cats. The isolates NCSU Tfs-1 (AF466749), NCSU Tbe (AF466750), and NCSU Tca (AF466751) came from a stray domestic long-hair cat from an animal shelter in Raleigh, North Carolina, a Bengal cat from a cattery in Charlotte, North Carolina, and a domestic short-hair cat from an animal shelter in San Diego, California, respectively. Trichomonads were isolated primarily from fresh stools $(<24 \mathrm{hr}$ from void) that had been stored at room temperature. Approximately $100 \mathrm{mg}$ of feces was diluted with $10 \mathrm{ml}$ PBS pH 7.0-7.4. Aliquots $(100 \mu \mathrm{l})$ of the diluted feces were then added to $10 \mathrm{ml}$ Remel's modified Diamond's medium (pH 6.9; Remel, Lenexa, Kansas), containing 100 units penicillin G, $150 \mu \mathrm{g}$ streptomycin sulfate, and $2 \mu \mathrm{g}$ amphotericin B per milliliter. Samples were incubated at 36-37 C in sterile, sealed, screw-capped, 15-ml, conical centrifuge tubes (Corning, Inc., Corning, New York). Cultures were passaged every 3-5 days by transferring $100 \mu 1$ into a new culture tube. After 3-4 passages with antibiotics, cultures were transferred to antibiotic-free media to confirm the absence of contaminating microorganisms. Parasites were either maintained in continuous passage or cryopreserved in liquid nitrogen using $10 \%$ dimethyl sulfoxide as a cryoprotectant. A bovine isolate of $P$. hominis (American Type Culture Collection [ATCC] \#30098) was cultured in both Remel's modified Diamond's medium and ATCC Medium 1404.

\section{Microscopy}

Silver staining for light microscopic analysis was prepared according to the method of $\mathrm{Ng}$ and Nelsen (1977). Scanning electron microscopy and transmission electron microscopy were performed as described by Dykstra (1993). For transmission electron microscopy, parasites were immersed in 5\% glutaraldehyde in 0.1 M Sorenson's buffer $(\mathrm{pH} 7.2$ 7.4) and stored at $4 \mathrm{C}$ for 4 days. The cells were centrifuged at 2,390 
$g$ for $30 \mathrm{sec}$, the fixative was removed with a pipet, and the cells were then rinsed in $0.1 \mathrm{M}$ sodium phosphate buffer ( $\mathrm{pH}$ 7.2). After centrifugation and a second rinse in buffer, the cells were resuspended in $3 \%$ water agar and quickly centrifuged a final time (Dykstra, 1993). After the agar solidified, the sample was cut into 1-mm-thick slices of agarized cells. The sample was placed in $1 \%$ osmium tetroxide in the same buffer for $1 \mathrm{hr}$ at room temperature. The sample was rinsed twice in distilled water and dehydrated in an ethanolic series culminating in 2 changes of $100 \%$ acetone. The sample was then placed in a mixture of resin (Spurr, 1969) and acetone (1:1) for $30 \mathrm{~min}$, followed by $2 \mathrm{hr}$ in $100 \%$ resin with 2 changes. Finally, the samples were placed in fresh $100 \%$ resin in molds and polymerized overnight. Semithin $(0.25-0.5$ $\mu \mathrm{m})$ sections were cut with glass knives and stained with $1 \%$ toluidine blue O sodium borate. Ultrathin $(70-90 \mathrm{~nm})$ sections were cut with a diamond knife, stained with methanolic uranyl acetate followed by lead citrate, and examined with a transmission electron microscope.

For SEM, a 50- $\mu 1$ droplet of PBS-washed cultured trichomonad cells was put onto a glass microscope slide under the cover of a petri dish, with a similar-sized droplet of $2 \%$ aqueous osmium tetroxide within approximately $2 \mathrm{~mm}$ of the cells. After $5 \mathrm{~min}$ at room temperature, the droplet of killed cells was transferred to a vial containing McDowell's and Trump's 4F:1G fixative (McDowell and Trump, 1976) for $1 \mathrm{hr}$ at room temperature. The cells were then pelleted for $30 \mathrm{sec}$ at 3,250 rcf, most of the fixative was removed, and the remaining pellet was resuspended in approximately $50 \mu \mathrm{l}$ of the fixative by vortexing. A pasteur pipet was used to put the droplet of fixed cells on a poly-L-lysine-coated coverslip in a moist chamber (Mazia et al., 1975). After $30 \mathrm{~min}$ the coverslip was rinsed twice in $0.1 \mathrm{M}$ sodium phosphate buffer $(\mathrm{pH} 7.2)$ and then dehydrated in a graded ethanol series to $100 \%$ ethanol, at which time the coverslip was critical point dried with liquid $\mathrm{CO}_{2}$. The coverslip was then mounted on a specimen stub with carbon tape, sputter-coated with approximately $20 \mathrm{~nm}$ of gold-palladium, and examined with a scanning electron microscope.

\section{Ribosomal RNA gene amplification and sequencing}

Trichomonad cultures in log phase growth were pelleted at $400 \mathrm{~g}$ for $10 \mathrm{~min}$. The pellets were washed 3 times by resuspending them in sterile PBS followed by centrifugation. Deoxyribonucleic acid was extracted from the washed pellets using the DNeasy Tissue kit (Qiagen, Valencia, California). Trichomonad 5.8S, internal transcribed spacer region (ITS) 1, ITS2, and partial 18S and 28S rRNA genes were amplified using the forward primer $5^{\prime}$ CCA TGC AAG TGT TAG TTC $3^{\prime}$ and the reverse primer $5^{\prime}$ TAG TTT CTT TTC CTC CGC $3^{\prime}$ in a RoboCycler ${ }^{\circledR}$ Gradient 96 temperature cycler (Stratagene, La Jolla, California). Polymerase chain reactions were carried out in a $50-\mu l$ volume, using $10 \times$ buffer (HotStarTaq, Qiagen), 2.5 U Taq polymerase (HotStarTaq, Qiagen), 10 $\mathrm{mM}$ of each deoxynucleoside triphosphate, and $100 \mathrm{ng}$ of each primer. The cycling conditions were $94 \mathrm{C}$ for $15 \mathrm{~min}$ once, then $94 \mathrm{C}$ for 45 $\mathrm{sec}, 58 \mathrm{C}$ for $45 \mathrm{sec}$, and $72 \mathrm{C}$ for $1.5 \mathrm{~min}$ for 40 cycles, followed by a final 5 min extension time at $72 \mathrm{C}$. The PCR products of Tfs- 1 and TCa were cloned into the pCR2.1 ${ }^{\circledR}$ cloning vector, and the Escherichia coli TOP $10^{\circledR}$ strain was transformed following the protocol of the supplier (Invitrogen, Carlsbad, California). Recombinants were selected by blue-white colony screening, and plasmid DNA from at least 3 clones for each isolate was isolated using the QIAprep ${ }^{\circledR}$ plasmid kit (Qiagen). Plasmids were analyzed for inserts by restriction enzyme digests, using EcoR1 at $37 \mathrm{C}$ for $30 \mathrm{~min}$, electrophoresed in a $1 \%$ agarose gel, stained with ethidium bromide, and viewed under UV light. Recombinant plasmids were sequenced in triplicate on an ABI373A DNA sequencer using Taq Dye Deoxy Terminator cycle-sequencing kit (ABI Biosystems, Foster City, California). The PCR product from the trichomonad isolate Tbe was purified using the Qiaquick PCR purification kit (Invitrogen) and sequenced directly. Nucleotide sequences were analyzed and compared using the Editseq and the Clustal V multiple-sequence alignment programs (DNASTAR, Madison, Wisconsin). To facilitate comparison with the trichomonad DNA sequences in GenBank ${ }^{\circledR}$, 2 separate alignments were constructed: one alignment of nearly complete 18S rRNA genes including the feline trichomonads, $T$. foetus (M81842 and U17509; all identifying numbers are GenBank accession numbers) and $P$. hominis (AF124609), and another alignment of the ITS1, 5.8S, and ITS2 sequences including the feline trichomonads, $T$. foetus (U85967 and M81842), T. suis (U85966), T. mobilensis (U86612), and P. hominis (AF156964 and U86616). The feline tricho-

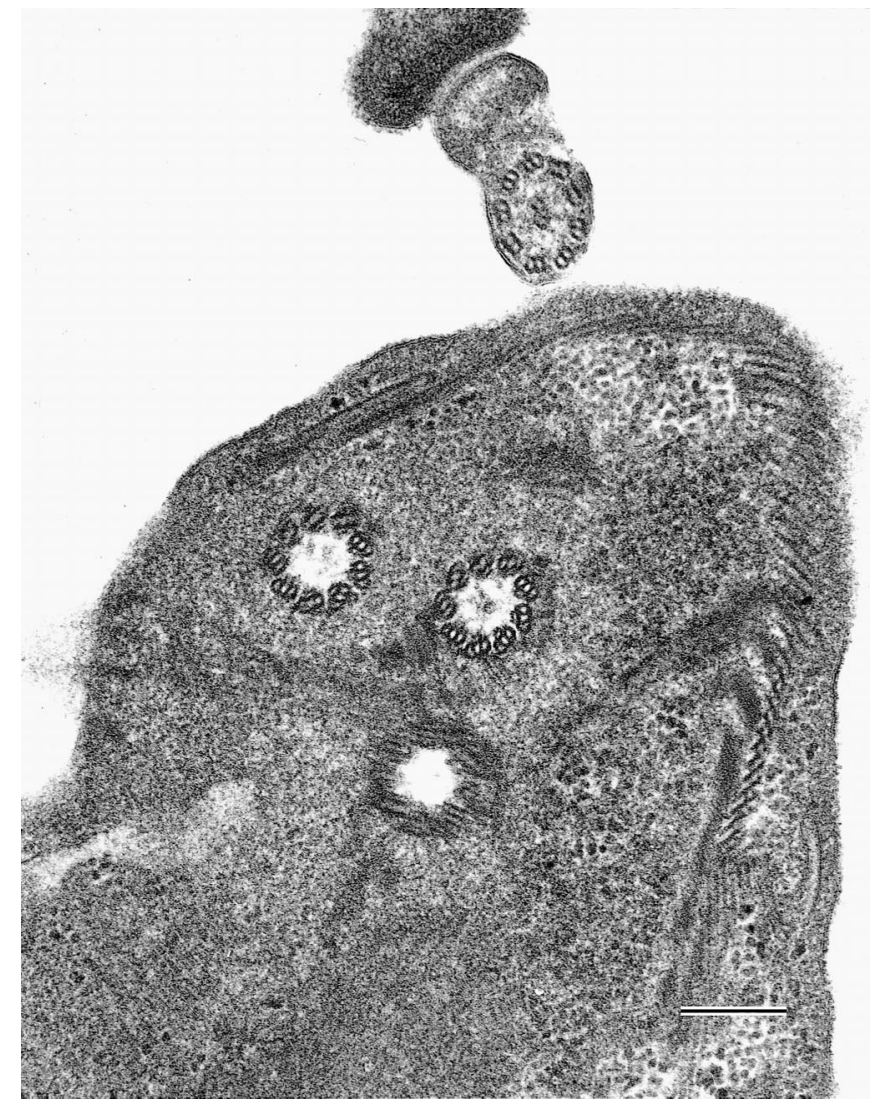

FIGURE 1. Tritrichomonas foetus NCSU Tfs-1 transmission electron micrograph showing 3 anterior flagella. Bar $=0.2 \mu \mathrm{m}$.

monad sequences determined in this study were assigned GenBank numbers AF466749-AF466751. Species-specific oligonucleotide primers were developed based on the differences between the published rRNA gene sequences for $P$. hominis, and the feline trichomonads, which had nearly complete sequence identity with the published rRNA gene sequences for $T$. foetus.

\section{Restriction fragment length polymorphism analysis}

For RFLP the PCR products were digested with EcoRV (Promega, Madison, Wisconsin) and analyzed by agarose gel electrophoresis and ethidium bromide staining.

\section{RESULTS}

Pentatrichomonas hominis grew very slowly and failed to thrive under conditions that supported luxuriant growth of the feline trichomonad isolates. Pentatrichomonas hominis could be passaged continuously only in ATCC Medium 1404. Phase contrast microscopic examination of osmium-fixed wet mounts of both trichomonads at either $\times 400$ or $\times 1,000$ magnification revealed that greater than $90 \%$ of the nondividing feline trichomonads in each sample possessed 3 anterior flagella. In contrast, the ATCC isolate of $P$. hominis had predominately 5 anterior flagella. Silver-stained feline trichomonads from culture also revealed 3 anterior flagella, with dimensions of $16.8 \pm 1.3$ $\mu \mathrm{m}$ by $10.6 \pm 1.2 \mu \mathrm{m}( \pm \mathrm{SD}, \mathrm{n}=100)$, an axostyle, and other morphology consistent with Tritrichomonas spp. (not shown). These observations were further confirmed by both transmission and scanning electron miscroscopic analysis (Figs. 1, 2).

An $\approx 1.9-\mathrm{kb}$ product was amplified from the feline tricho- 


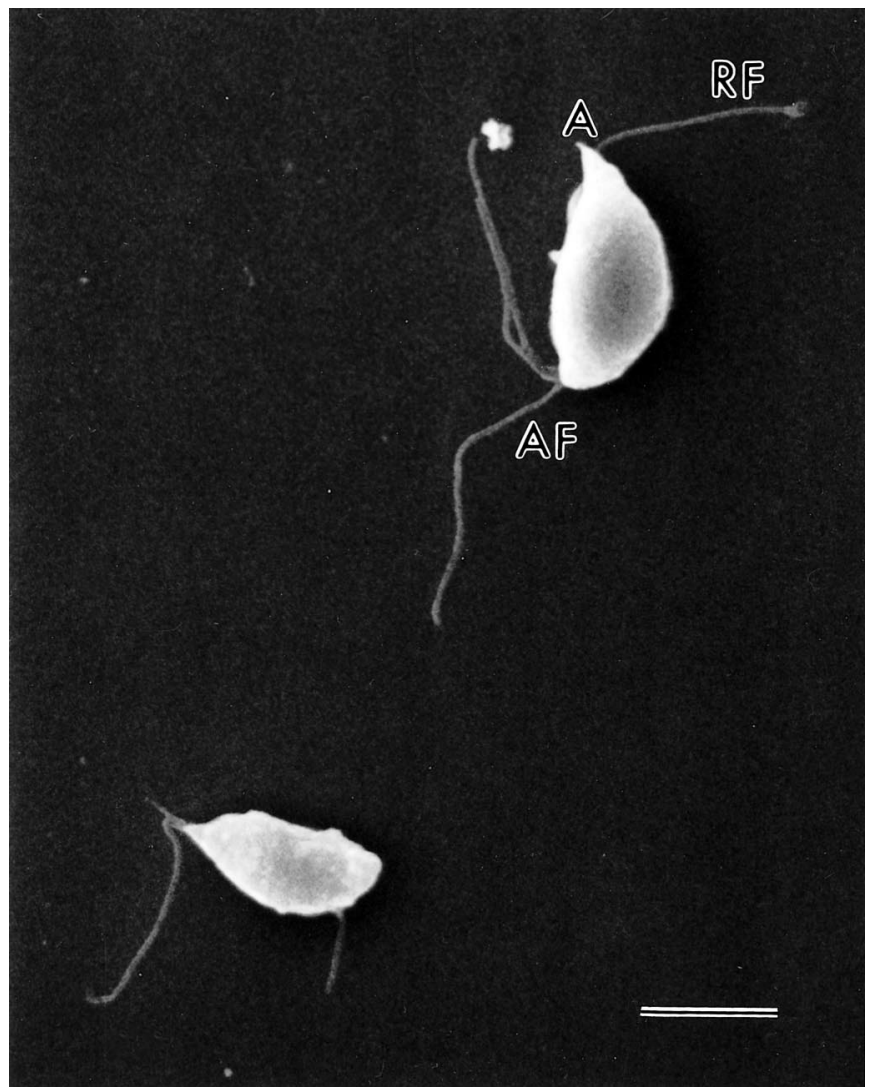

FIGURE 2. Tritrichomonas foetus NCSU Tfs-1 scanning electron micrograph showing anterior flagella (AF), recurrent flagella (RF), and axostyle (A). Bar $=0.5 \mu \mathrm{m}$.

monad and $P$. hominis isolates. The feline trichomonads and $P$. hominis restriction enzyme digest patterns were different and as predicted based on the published sequences for $T$. foetus and $P$. hominis (Fig. 3). The DNA sequences from the 3 feline trichomonad isolates were identical. Both the $18 \mathrm{~S}$ and the ITS1, 5.8S, and ITS2 alignments demonstrate that the feline trichomonads are nearly sequence identical $(99.5-100 \%)$ to $T$. foetus and that the feline trichomonads share a low degree of sequence identity (56.6-82.6\%) with $P$. hominis (Fig. 4).

\section{DISCUSSION}

In the early part of the 20th century, there were several reports of trichomonads in the intestinal tract or feces of domestic cats in Brazil (Da Cunha and Muniz, 1922), France (Brumpt, 1925), Yugoslavia (Simic, 1932), and China (Kessel, 1928). Except for the report by Kessel (1928), clinical signs associated with gastrointestinal disease were not reported. Although there were several early reports of experimental trichomonad infections in cats (Brumpt, 1922; Kessel, 1928; Henger and Eskridge, 1935), clinical disease was either not reported or difficult to interpret because of the lack of strictly controlled experimental infections. Intestinal trichomonads in the cat are considered to be dubious pathogens by most veterinary authorities (Levine, 1985; Dimski, 1989; Burrows et al., 1995; Barr, 1998), with most authors assigning them the role of opportunistic parasites whose numbers may increase dramatically in the presence

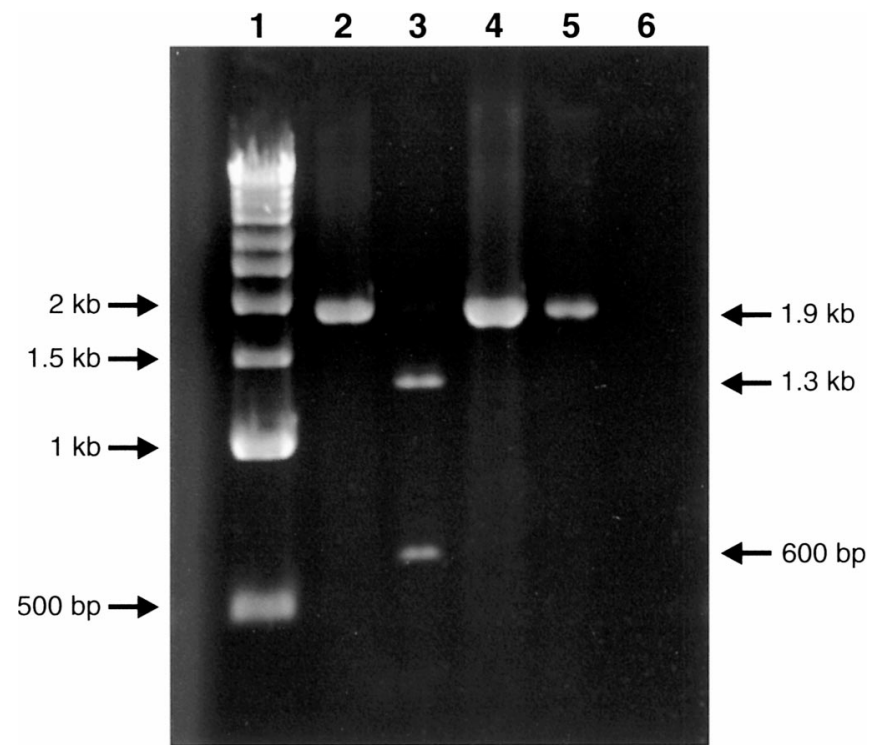

FIGURE 3. Restriction fragment length polymorphism agarose gels showing digestion of rRNA genes of Tritrichomonas foetus NCSU Tfs1 and Pentatrichomonas hominis (ATCC \#30098). The $\approx 1,900-\mathrm{kb}$ PCR product of the rRNA genes was digested with EcoRV and separated on a 4\% agarose gel. Lane 1, kb markers; lanes 2 and 4, nondigested $T$. foetus and $P$. hominis, respectively; lanes 3 and 5, PCR products of $T$. foetus and P. hominis, respectively, digested with EcoRV; lane 6, no DNA control.

of altered large-bowel physiology. However, there have been several recent reports of a trichomonad, described as $P$. hominis, from the stools of naturally infected cats suffering from large-bowel diarrhea (Romatowski, 1996, 2000; Gookin et al., 1999). Experimental infection of SPF, as well as Cryptosporidium-infected, cats with axenically cultivated isolates of NCSU Tfs- 1 trichomonads from the stools of a naturally infected cat resulted in reproduction of the disease syndrome, fulfilling Koch's postulates (Gookin et al., 2001). Thus, this feline trichomonad isolate can now be considered to be a primary pathogen in this host as well.

Tritrichomonas has been placed within the Tritrichomonadinae and exhibits 3 anterior flagella, a stout axostyle with periaxostylar rings, a stout costa, and a small pelta. The parabasal body is either rod- or sausage-shaped, and a relatively stout costa is present (Honigberg, 1963). In contrast, Pentatrichomonas has been placed within the Trichomonadida and is characterized by a predominance of 5 anterior flagella, a comparatively slender axostyle lacking periaxostylar rings, and a slender costa and parabasal body varying in size and shape. The light and electron microscopic analyses of the feline trichomonads described in this report are consistent with the morphologic description of $T$. foetus and not with that of $P$. hominis.

Tritrichomonas foetus is recognized as a serious venereal pathogen of the reproductive tract of the cow, which may develop vaginitis, cervicitis, endometritis, or pyometra. Abortion is a common sequela to infection, and economic losses in naturally bred cattle in the United States and worldwide may be substantial (Kvasnicka et al., 1998). The closely related or synonymous species, $T$. suis, is able to infect various sites in the pig, including the nasal cavity and the cecum. However, pathogenicity for swine remains uncertain. Tritrichomonas suis has 
A

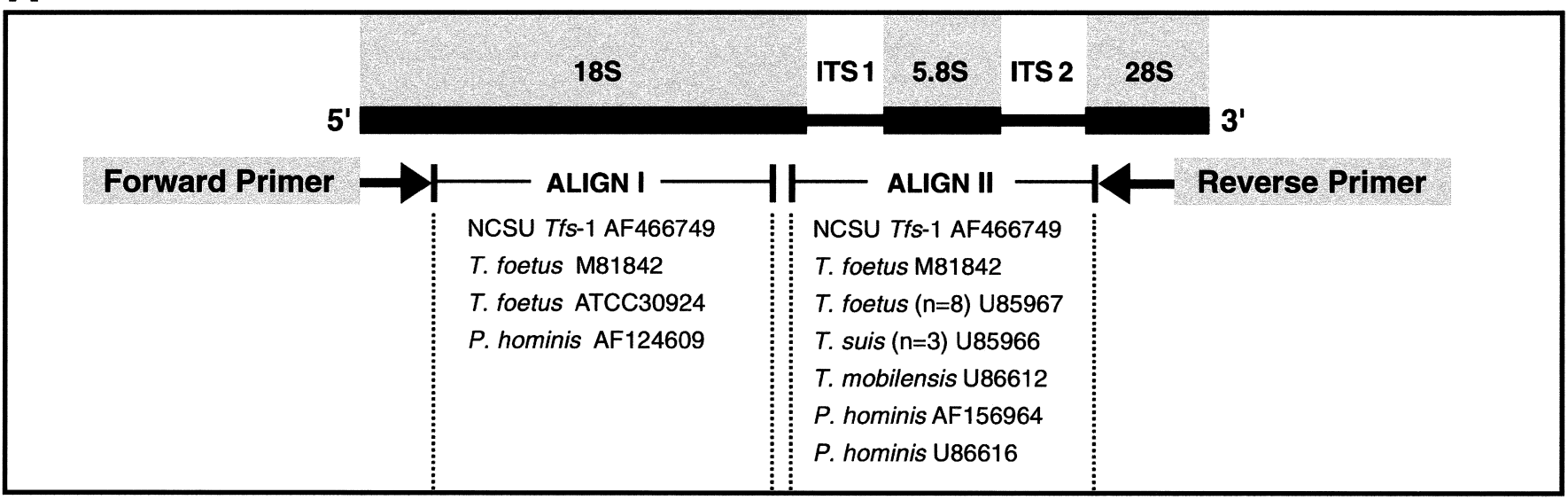

B

\begin{tabular}{|c|c|c|c|c|}
\hline $\begin{array}{c}\text { T. foetus } \\
\text { (M81842) }\end{array}$ & $\begin{array}{c}\text { NCSU Tfs-1 } \\
\text { (AF466749) }\end{array}$ & $\begin{array}{c}\text { T. foetus } \\
\text { (ATCC30924) }\end{array}$ & $\begin{array}{c}\text { P. hominis } \\
\text { (AF124609) }\end{array}$ & \\
\hline & 100.00 & 99.7 & 82.6 & $\begin{array}{c}\text { T. foetus } \\
\text { (M81842) }\end{array}$ \\
\hline & 99.7 & 82.6 & $\begin{array}{c}\text { NCSU Tfs-1 } \\
\text { (AF466749) }\end{array}$ \\
\hline & & 82.4 & $\begin{array}{c}\text { T. foetus } \\
\text { (ATCC30924) }\end{array}$ \\
\hline & & & $\begin{array}{c}\text { P. hominis } \\
\text { (AF124609) }\end{array}$ \\
\hline
\end{tabular}

C

\begin{tabular}{|c|c|c|c|c|c|c|c|}
\hline $\begin{array}{c}\text { T. foetus } \\
\text { (M81842) }\end{array}$ & $\begin{array}{c}\text { NCSU Tfs-1 } \\
\text { (AF466749) }\end{array}$ & $\begin{array}{c}\text { T. foetus } \\
\text { (U85967) }\end{array}$ & $\begin{array}{c}\text { T. suis } \\
\text { (U85966) }\end{array}$ & $\begin{array}{l}\text { T.mobilensis } \\
\text { (U86612) }\end{array}$ & $\begin{array}{c}\text { P. hominis } \\
\text { (AF156964) }\end{array}$ & $\begin{array}{c}\text { P. hominis } \\
\text { (U86616) }\end{array}$ & \\
\hline & 99.5 & 99.7 & 99.7 & 99.5 & 57.4 & 56.9 & $\begin{array}{c}\text { T. foetus } \\
\text { (M81842) }\end{array}$ \\
\hline & 99.7 & 99.7 & 99.5 & 57.1 & 56.6 & $\begin{array}{l}\text { NCSU Tfs-1 } \\
\text { (AF466749) }\end{array}$ \\
\hline & & 100.0 & 99.7 & 57.4 & 56.9 & $\begin{array}{c}\text { T. foetus } \\
\text { (U85967) }\end{array}$ \\
\hline & & & 99.7 & 57.4 & 56.9 & $\begin{array}{c}\text { T. suis } \\
\text { (U85966) }\end{array}$ \\
\hline & & & & 57.1 & 56.3 & $\begin{array}{c}\text { T. mobilensis } \\
\text { (U86612) }\end{array}$ \\
\hline & & & & & 98.2 & $\begin{array}{l}\text { P. hominis } \\
\text { (AF156964) }\end{array}$ \\
\hline & & & & & & & \\
\hline
\end{tabular}

FIGURE 4. A. Graphic representation of the rRNA gene operon of Tritrichomonas foetus, T. suis, T. mobilensis, and Pentatrichomonas hominis with respect to the oligonucleotide primers and alignments. B. Sequence identity table comparing feline $T$. foetus, bovine isolates of $T$. foetus, and $P$. hominis with respect to the $18 \mathrm{~S}$-like rRNA gene. C. Sequence identity table comparing feline T. foetus, T. foetus, T. suis, T. mobilensis,

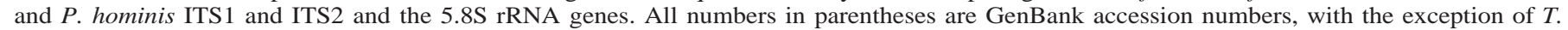

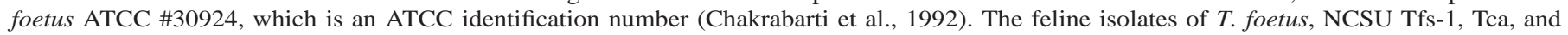
Tbe, had complete sequence identity.

been shown to cause vaginal pathology similar to that caused by bovine isolates of $T$. foetus when transferred to ruminants (Switzer, 1951; Hammond and Leidl, 1957; Fitzgerald et al., 1958). Tritrichomonas mobilensis was originally isolated from a squirrel monkey with diarrhea. Specific pathology could not be attributed to this organism in the squirrel monkey. However, cocultivation of this trichomonad with tissue-cultured cells resulted in cytopathological changes (Pindak et al., 1985). Infection with $T$. mobilensis was also associated with liquid cecal contents in the tree shrew Tupaia belangeri (Brack et al., 1995).

Intestinal flagellates identified as $P$. hominis, but exhibiting either 3, 4, or 5 anterior flagella, have been reported from a wide variety of mammalian hosts, including humans, a number of nonhuman primates, cats, dogs, and rodents (see Levine 1973 for a review). Tritrichomonas sp. and Pentatrichomonas sp. are not easily differentiated from each another by examining living material or organisms stained with routinely used histological stains. Anterior flagella are difficult to enumerate in living motile specimens, and axostyle morphology, which is an important criterion for distinguishing tritrichomonads from pentatricho- monads, requires specialized silver-staining techniques for adequate viewing. Our earlier tentative identification of $P$. hominis as the organism associated with clinical disease in the cat (Gookin et al., 1999) was based on previous reports that the trichomonads from the intestinal tract of cats, dogs, or other species that have 3-5 anterior flagella were $P$. hominis. Furthermore, until recently, other species of trichomonads of similar appearance from the cat have not been described. Differential identification of intestinal flagellates of similar appearance requires special stains, species-specific (Hodgson et al., 1990) antibodies, or detailed microscopic examination by highly trained specialists, techniques not generally available in routine veterinary diagnostics. It is more than likely that other investigators have made the same error when identifying feline fecal trichomonads. Numerous veterinary clinicians have mistakenly identified the motile feline trichomonad trophozoites as Giardia sp., which often resulted in delayed diagnosis and inappropriate therapy (M. Levy and J. Gookin, unpubl. data). Adding to the confusion, we now know that hosts other than cats have been demonstrated to simultaneously harbor both $P$. 
hominis and Tritrichomonas species. For example, Pindak et al. (1985) reported both $P$. hominis and an unidentified Tritrichomonas sp., later described as T. mobilensis (Culberson et al., 1986), from the intestines of the squirrel monkeys (Saimiri scireus).

The taxonomic relationship among the species of Tritrichomonas remains unsettled, with various authors concluding that the separation of $T$. foetus from $T$. suis, and perhaps $T$. mobilensis, may be unjustified based on cross-transmission studies (Fitzgerald et al., 1958; Kerr, 1958) and biochemical, antigenic, (Switzer, 1951; Doran, 1957; Robertson, 1960; De Carli and Guerrero, 1976; Pakandl and Grubhoffer, 1994; Mattos et al., 1997), or genetic analysis (Felleisen, 1997; Hampl et al., 2001). The precise phylogeny of $T$. foetus based on this gene is currently unresolved (Gunderson et al., 1995; Edgecomb et al., 1998; Delgado-Viscogliosi et al., 2000). Felleisen (1997) concluded that either the various species of Tritrichomonas diverged recently in evolutionary time, so that species differences are not reflected in the rRNA genes, or that T. foetus, T. suis, and perhaps T. mobilensis should be considered strains of the same species. Specifically, he compared the ITS1, 5.8S, and ITS2 regions from 9 isolates of T. foetus, 3 isolates of $T$. suis, and a single isolate of $T$. mobilensis and found that a single $T$. foetus strain differed only at 1 position. This 1 base-pair difference may likely be due to either a sequencing error or normal variation within the multiple copies of the RNA genes in any given genome. Random amplified polymorphic DNA analysis similarly indicated that $T$. foetus was synonymous with $T$. suis (Hampl et al., 2001). More recently, Tachezy et al. (2002) compared the ultrastructure, pathogenicity, and DNA polymorphism of $T$. foetus and $T$. suis and also concluded that they were cospecific. Regardless of the final taxonomic position of T. foetus, T. suis, and T. mobilensis, previous analysis of the rRNA genes, based on secondary structure, clearly placed Tritrichomonas spp. in a clade separate from Pentatrichomonas spp. (DelgadoViscogliosi et al., 2000). The near sequence identity of the feline trichomonad rRNA genes described in this report to $T$. foetus supports the classification of these feline trichomonads as $T$. foetus and not as $P$. hominis.

The morphologic and genetic analyses described in this study clearly indicate that the feline intestinal trichomonad associated with feline diarrheal disease is indistinguishable from $T$. foetus. As our culture technique was not able to support $P$. hominis, we could not rule out the possibility of naturally occurring dual infections in our study animals. We have, however, examined hundreds of freshly prepared wet mounts from numerous cases of clinical feline trichomonal diarrhea, and all the organisms observed so far appear to be identical to the culture isolates (Gookin et al., 1999; M. Levy and J. Gookin, unpubl. data).

Cats experiencing $T$. foetus-associated diarrhea commonly have cow-pie stools, often associated with fecal incontinence, resulting in contamination of the cat's coat and environment with infectious trophozoites. As previously described, there is a lack of strict host specificity for T. foetus or T. suis. Tritrichomonas mobilensis, a closely related, or perhaps synonymous, species, also has been reported to infect nonhuman primates. Because of close contact between humans and cats, human exposure may be a relatively frequent event. A fatal human meningitis infection by $T$. foetus has been reported recently from an immunosuppressed human (Okamoto et al., 1998). The source of infection was not identified in this case.

Human infections with intestinal trichomonads would most likely be diagnosed by a microscopic examination of wet mounts of freshly passed nonrefrigerated stools, a procedure that is a relatively uncommon medical practice in the developed world. Additionally, if trophozoites are observed in human stools, they might be easily mistaken for either Giardia sp. trophozoites or $P$. hominis, as has been the case among veterinary diagnosticians. The lack of effective chemotherapeutants for treatment of the feline isolate (Levy et al., 2000) is consistent with the current ineffectiveness of therapy for bovine trichomoniasis (Kvasnicka et al., 1998). This situation, along with its uncertain zoonotic potential, makes this infection especially problematic to manage. The role of the bovine in the ecology and epidemiology of feline trichomoniasis warrants further investigation.

\section{LITERATURE CITED}

BARR, S. C. 1998. Enteric protozoal infections. In Infectious diseases of the dog and cat, 2nd ed., C. E. Greene (ed.). W. B. Saunders, Philadelphia, Pennsylvania, p. 487.

BRACK, M., F. J. KAUP, AND E. FuCHS. 1995. Intestinal trichomoniasis due to Tritrichomonas mobilensis in tree shrews (Tupaia belangeri). Laboratory Animal Science 45: 533-537.

BRUMPT, E. 1922. Recherches morphologiques et experimentales sur le Trichomonas felis da cunha et muniz, parasite du chat et du chien. Annals of Parasitology 3: 239-251.

Burrows, C. F., R. M. BAtT, AND R. G. Sherding. 1995. Diseases of the small intestine, 4th ed. In Textbook of veterinary internal medicine, 4th ed., S. J. Ettinger, and E. C. Feldman (eds.). W. B. Saunders, Philadelphia, Pennsylvania, p. 1169-1232.

Chakrabarti, D., J. B. Dame, R. R. Gutell, and C. A. Yowell. 1992. Characterization of the rDNA unit and sequence analysis of the small subunit rRNA and 5.8S rRNA genes from Tritrichomonas foetus. Molecular and Biochemical Parasitology 52: 75-84.

Culberson, D. E., F. F. Pindak, W. A. Gardner, and B. M. Honigberg. 1987. Tritrichomonas mobilensis n. sp. (Zoomastagophera: Trichomonadida) from the Bolivian squirrel monkey Saimiri bolivensis bolivensis. Journal of Protozoology 33: 301-304.

Da Cunha, A. M., And J. Muniz. 1922. Trabalhos do Instituto Oswaldo Cruz. Sombre um flagellado parasitito do gato. Brazil-Medico 36: 285-286.

De Carli, A., And J. Guerrero. 1976. Antigenic comparison between Tritrichomonas suis and T. foetus II. Gel immunodiffusion. Revista Latinoamericana de Microbiologia 18: 167-171.

Delgado-Viscogliosi, P., E. Viscogliosi, P. Gerbod, J. Kulda, M. L. Sogin, AND V. P. EdGECOMB. 2000. Molecular phylogeny of the parabasilids based on small subunit rRNA sequences, with emphasis on the Tritrichomonad subfamily. Journal of Eukaryotic Microbiology 47: 70-75.

DIMSKI, D. S. 1989. Helminth and noncoccidial protozoan parasites of the gastrointestinal tract. In The cat: Diseases and clinical management, 2nd ed., R. G. Sherding (ed.). Churchill Livingston, New York, New York, p. 459-477.

Doran, D. J. 1957. Studies on trichomonads. I. The metabolism of Tritrichomonas foetus and trichomonads from the nasal cavity and cecum of swine. Journal of Protozoology 4: 182-190.

DYKSTRA, M. J. 1993. A manual of applied techniques for biological electron microscopy. Plenum Press, New York, New York, 257 p.

Edgecomb, V. P., E. Viscogliosi, G. B. Simpson, P. Delgado-ViscogLiosi, AND M. L. SogIN. 1998. New insights into the phylogeny of trichomonads inferred from small subunit rRNA sequences. Protista 149: $359-366$.

FELleisen, R. S. J. 1997. Comparative sequences analysis of the 5.8S rRNA genes and internal transcribed spacer (ITS) regions of trichomonad protozoa. Parasitology 115: 111-119.

Fitzgerald, P. R., A. E. Johnson, D. M. Hammond, J. L. Thorne, And 
C. P. Hibler. 1958. Experimental infection of young pigs following intranasal inoculation with nasal, gastric, or cecal trichomonads from swine or with Trichomonas foetus. Journal of Parasitology 44: 597-602.

Gookin, J. L., E. B. Breitschwerdt, M. G. Levy, R. B. Gager, And J. G. BENRUD. 1999. Diarrhea associated with trichomonosis in cats. Journal of the American Veterinary Medical Association 10: 1450 1454.

, M. G. Levy, J. M. Law, M. G. Papich, M. F. Poore, and E B. BreitschwerdT. 2001. Experimental infection of cats with Tritrichomonas foetus. American Journal of Veterinary Research 62: 1690-1697.

Gunderson, J., G. Hinkle, D. Leipe, H. G. Morrison, S. K. Stickel, D. A. Odelson, J. A. Beznak, T. A. Nerat, M. Müller, And M L. SogIN. 1995. Phylogeny of trichomonads inferred from small subunit rRNA sequences. Journal of Eukaryotic Microbiology 42: 411-415.

Hammond, D. M., AND W. LeIDL. 1957. Experimental infections of the genital tract of swine and goats with Trichomonas foetus and Trichomonas species from the cecum and feces of swine. American Journal of Veterinary Research 18: 461-465.

Hampl, V., A. PavliceK, And J. Flegr. 2001. Construction and bootstrap analysis of DNA fingerprinting-based phylogenetic trees with the freeware program FreeTree: Application to trichomonad parasites. International Journal of Systematic and Evolutionary Microbiology 51: 731-735.

Henger, R., AND L. ESKRIDGE. 1935. Absence of pathogenicity in cats infected with Trichomonas felis from cats and Trichomonas hominis from man. American Journal of Hygiene 22: 322-325.

Hodgson, J. L., D. W. Jones, P. R. Widders, And L. B. CorbeIl. 1990. Characterization of Tritrichomonas foetus antigens by use of monoclonal antibodies. Infection and Immunity 58: 3078-3083.

HonigBerg, B. M. 1963. Evolutionary and systematic relationship in the flagellate order Trichomonadida Kirby. Journal of Protozoology 10: $20-63$.

KERR, W. R. 1958. Experiments in cattle with Trichomonas suis. Veterinary Record 70: 613-615.

Kessel, J. F. 1928. Trichomoniasis in kittens. Transactions of the Royal Society of Tropical Medicine and Hygiene 22: 61-80.

KvasnickA, W. G., M. R. HAll, AND D. R. HANKs. 1998. Bovine trichomoniasis. In Current veterinary therapy 4. Food animal practice, J. L. Howard and R. A. Smith (eds.). W. B. Saunders, Philadelphia, p. 420-425.

LeVINE, N. D. 1973. Protozoan parasites of domestic animals and of man, 2nd ed. Burgess Publishing, Minneapolis, Minnesota, 406 p. - 1985. Veterinary protozoology. Iowa State University Press, Ames, Iowa, $414 \mathrm{p}$.

Levy, M. G., J. L. Gookin, M. F. Poore, M. G. Papich, And E. B. Breitschwerdt. 2000. Intestinal trichomonosis in cats: Pathology, diagnosis and susceptibility to antiprotozoal drugs. In Proceedings of the joint meeting of the American Society of Parasitologists and the Society of Protozoologists. San Juan, Puerto Rico, p. 108. (Abstract.)

Mattos, A., A. M. Sole-Cava, G. DeCarli, And M. Benchimol. 1997. Fine structure and isozymic characterization of trichomonadid protozoa. Parasitology Research 83: 290-295.

Mazia, D., G. Schatten, And W. Sale. 1975. Adhesion of cells to surfaces coated with polylysine. Journal of Cell Biology 66: 198200.

McDowell, E. M., AND B. F. Trump. 1976. Histologic fixatives suitable for diagnostic light and electron microscopy. Archives of Pathology and Laboratory Medicine 100: 405-414.

NG, S. F., AND E. M. NELSEN. 1977. The protargal staining technique: and improved version for Tetrahymena pyriformis. Transactions of the American Microscopical Society 96: 369-376.

Okamoto, S., M. Wakui, H. Kobayashi, N. SAto, A. Ishida, M. TANabe, T. Takeuchi, S. Fukushima, T. Yamada, Y. IkedA, and Y. KEIO. 1998. Trichomonas foetus meningoencephalitis after allogeneic peripheral blood stem cell transplantation. Bone Marrow Transplant 21: 89-91.

PAKANDL, M., AND L. GrubhofFer. 1994. Some properties of the sialicacid binding systems in Tritrichomonas suis and Tritrichomonas foetus. Comparative Biochemistry and Physiology 108B: 529-536.

Pindak, F. F., M. Mora de Pindak, C. R. Abee, and W. A. Gardner JR. 1985. Detection and cultivation of intestinal trichomonads of squirrel monkeys (Saimiri sciureus). American Journal of Primatology 9: 197-205.

RoBERTSON, M. 1960. The antigens of Tritrichomonas foetus isolated from cows and pigs. Journal of Hygiene (Cambridge) 58: 207-212.

Romatowski, J. 1996. An uncommon protozoan parasite (Pentatrichomonas hominis) associated with colitis in three cats. Feline Practice 24: $10-14$.

2000. Pentatrichomonas hominis infection in four kittens. Journal of the American Veterinary Medical Association 216: 12701272.

Simic, T. S. H. 1932. Etude biologique et experimental du Trichomonas intestinalis, infectant spontanement l'homme, le chat et le chien. Annals of Parasitology 10: 209-224.

SPURR, A. R. 1969. A low-viscosity epoxy resin embedding medium for electron microscopy. Journal of Ultrastructural Research 26: 3143.

SwITZER, W. P. 1951. Atropic rhinitis and trichomonads. Veterinary Medicine 46: 478-481.

Tachezy, J., R. Tachezy, V. Hampl, M. Edinova, J. Flegr, and J. KULDA. 2002. Cattle pathogen Tritrichomonas foetus (Riedmüller, 1928) and pig commensal Tritrichomonas suis (Gruby \& Delafond, 1843 ) belong to the same species. Journal of Eukaryotic Microbiology 49: 54-163. 